\title{
Diastolic closure rate of normal mitral valve
}

\author{
Clive Layton, Graham Gent,' Ronald Pridie, Alastair McDonald, and Wallace Brigden \\ From the Cardiac Department, The London Hospital, Whitechapel, London
}

In order to establish the determinants of the diastolic closure rate of the mitral valve measured from echocardiographic recordings, 5 normal volunteers have been studied by non-invasive methods and 20 patients in the course of cardiac catheterization. No correlation was found between the heart rate and the diastolic closure rate, but a linear relation was established between the left ventricular filling pressure and the diastolic closure rate. The coefficients of regression of the equations obtained from the individual regression lines were linearly related to left ventricular diastolic $\triangle P \mid \triangle V$ and the constants of the equations were related in a linear fashion to the total amplitude of movement of the mitral valve ring.

These findings support the hypothesis that the diastolic closure rate of the structurally normal mitral valve reflects the rate of left ventricular filling, and also confirm the importance of movement of the valve ring in the composite pattern ascribed to the motion of the anterior cusp assessed by echocardiography. Analysis of mitral valve movement coupled with haemodynamic measurements may provide useful information relating to left ventricular compliance.

Recording of the movement of the anterior cusp of the mitral valve using reflected ultrasound has been increasingly used in clinical practice. Variations in the pattern of movement have been described in heart disease, and it has been established that measurement of the. speed with which the mitral valve closes in early diastole, the diastolic closure rate, is of considerable diagnostic value (Gustafson, 1967; Segal, Likoff, and Kingsley, 1967). Low levels of the diastolic closure rate have been observed in mitral stenosis (Edler, 1956) and in hypertrophic cardiomyopathy (Popp and Harrison, 1969; Pridie and Oakley, 1970; Shah, Gramiak, and Kramer, I969; Moreyra et al., 1969) while high levels are found in mitral or aortic regurgitation (Segal et al., 1967; Pridie, 1969) and in some cases of myocardial infarction (Tallury, DePasquale, and Burch, 1972). On the basis of these observations it has been suggested that the diastolic closure rate may reflect the rate of left ventricular filling (Segal et al., 1967), but we are unaware of any physiological studies to substantiate this hypothesis or to establish the factors which determine the diastolic closure rate of the normal mitral valve.

It has also been recognized that movement of the mitral valve ring contributes to the apparent move-

Received 7 June I973.

1 This study has been supported by grants from the British Heart Foundation. ment of the anterior cusp (Chakorn et al., 1972), but no studies have been performed to quantify this relation or the factors governing it. Such information is required if the abnormal findings in myocardial or valvular disease are to be interpreted correctly, and to explain the changes in behaviour of the mitral valve in the presence of left ventricular disease without organic valve disease. This study has been designed to assess the importance of the heart rate, the left ventricular filling pressure, the left ventricular diastolic pressure/ volume relation, the stroke volume, and the movement of the mitral valve ring as determinants of the diastolic closure rate of the anatomically normal mitral valve.

\section{Subjects}

The investigation was performed in two parts. In the first section 5 normal male volunteers, age range 26 to 47 years, were studied using non-invasive recording techniques for the assessment of the cardiovascular response to changes in the heart rate. In the second part 20 patients undergoing diagnostic cardiac catheterization were studied, including 13 with coronary artery disease, 4 with cardiomyopathy, I with hypertension, I with cardiomyopathy with left ventricular inflow tract obstruction, and I with persistent chest pain in whom no cardiac or coronary abnormality has been shown. Clinical details of these patients are shown in Table I. Informed consent for the research aspects of this study was obtained from all the subjects investigated. Mitral and aortic 
TABLE I Clinical, haemodynamic, and echocardiographic data from 20 patients

\begin{tabular}{|c|c|c|c|c|c|c|c|c|c|}
\hline Case No. & Age & Sex & Diagnosis & $\begin{array}{l}\text { Mean } \\
\text { LVEDP } \\
(m m H g)\end{array}$ & $\begin{array}{l}\text { Heart } \\
\text { rate/min }\end{array}$ & $\begin{array}{l}\text { Stroke } \\
\text { volume } \\
(m l)\end{array}$ & $\begin{array}{l}\text { Diastolic } \\
\Delta P / \Delta V \\
(m m H g / m l)\end{array}$ & $\begin{array}{l}\text { Mean diastolic } \\
\text { closure rate } \\
(\mathrm{mm} / \mathrm{sec})\end{array}$ & $\begin{array}{l}\text { Mean } \\
\text { amplitude of } \\
\text { ring movement } \\
(\mathrm{mm})\end{array}$ \\
\hline $\mathbf{I}$ & $6 I$ & $\mathbf{M}$ & Coronary artery disease & II & 68 & 91 & 0.110 & 103 & - \\
\hline 2 & 58 & $\mathbf{M}$ & Coronary artery disease & 15 & IOI & 30 & 0.445 & 38 & - \\
\hline 3 & 62 & $\mathbf{M}$ & Coronary artery disease & 6 & 65 & 85 & 0.118 & 51 & - \\
\hline 4 & 52 & $\mathbf{M}$ & Cardiomyopathy & 24 & 104 & 46 & 0.341 & II I & - \\
\hline 5 & 58 & $\mathbf{F}$ & Hypertension & II & 75 & 54 & 0.236 & 37 & - \\
\hline 6 & 63 & $\mathbf{M}$ & Coronary artery disease & 15 & 77 & 39 & 0.178 & 63 & - \\
\hline \multirow[t]{2}{*}{7} & $6 I$ & $\mathbf{M}$ & $\mathrm{LV}$ inflow & & & & & & \\
\hline & & & obstruction & 32 & IOI & 29 & 0.586 & 29 & - \\
\hline 8 & 50 & $\mathbf{M}$ & Coronary artery disease & 13 & 75 & 55 & 0.355 & 80 & - \\
\hline 9 & 54 & $\mathbf{M}$ & Coronary artery disease & 13 & 73 & 54 & 0.326 & 46 & $7 \cdot 0$ \\
\hline Io & 44 & $\mathbf{M}$ & Coronary artery disease & IO & 55 & 74 & 0.106 & 120 & $15 \cdot 7$ \\
\hline II & 56 & $\mathbf{M}$ & Coronary artery disease & 13 & - & - & - & 129 & $10 \cdot 0$ \\
\hline 12 & 46 & $\mathbf{M}$ & Coronary artery disease & I0 & 74 & 48 & 0.230 & 55 & II $\cdot 0$ \\
\hline 13 & $6 I$ & $\mathbf{F}$ & Coronary artery disease & 13 & 65 & 45 & 0.320 & $6 I$ & $8 \cdot 9$ \\
\hline 14 & 48 & $\mathbf{M}$ & Normal & 7 & 80 & 102 & 0.081 & 82 & $13 \cdot 4$ \\
\hline \multirow[t]{2}{*}{15} & 60 & $\mathbf{F}$ & Coronary artery disease & & & & & & \\
\hline & & & & (PADP) & 一 & - & 一 & IOI & $12 \cdot 0$ \\
\hline \multirow[t]{2}{*}{16} & 43 & $\mathbf{M}$ & Coronary artery disease & 13 & & & & & \\
\hline & & & & (PADP) & - & - & - & 83 & $10 \cdot 0$ \\
\hline \multirow[t]{2}{*}{$\begin{array}{l}17 \\
18\end{array}$} & $\begin{array}{l}39 \\
44\end{array}$ & $\begin{array}{l}\mathbf{F} \\
\mathbf{M}\end{array}$ & $\begin{array}{l}\text { Cardiomyopathy } \\
\text { Amyloid }\end{array}$ & 16 & 72 & 71 & 0.108 & 73 & $6 \cdot 7$ \\
\hline & & & cardiomyopathy & 37 & 105 & 55 & 0.590 & 66 & $7 \cdot 6$ \\
\hline 19 & 18 & $\mathbf{M}$ & Cardiomyopathy & 21 & 89 & 87 & 0.190 & 73 & 8.9 \\
\hline 20 & 55 & $\mathbf{M}$ & Coronary artery disease & 16 & 67 & 47 & 0.220 & 93 & $8 \cdot 7$ \\
\hline
\end{tabular}

LVEDP = left ventricular end-diastolic pressure; $P A D P=$ pulmonary artery diastolic pressure.

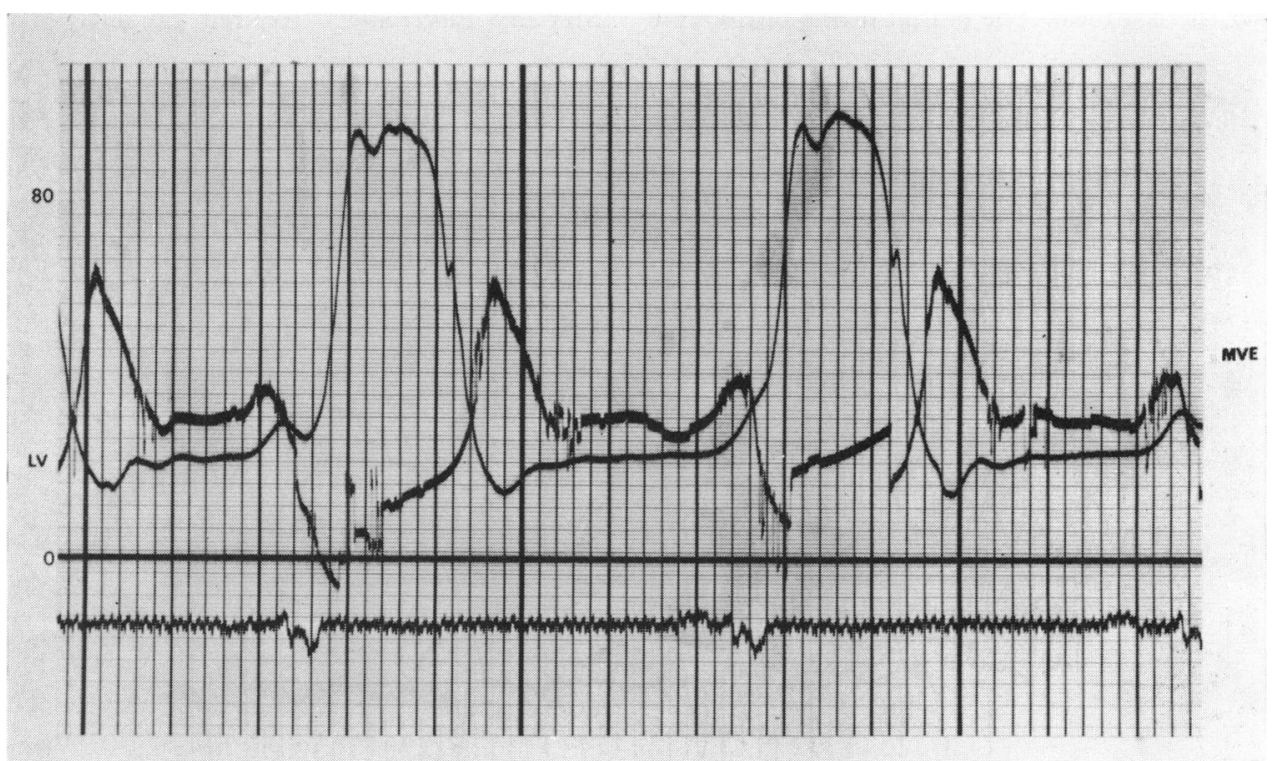

FIG. I The normal mitral echogram with simultaneous electrocardiogram and left ventricular pressure. 
regurgitation were excluded in all as were the presence of any intracardiac shunts.

\section{Methods}

The mitral valve echogram was recorded using a SmithKline Instruments Ekoline 20 ultrasound recorder providing a repetition rate of 1000 pulses a second with a frequency of $2.5 \mathrm{mega} \mathrm{Hz}$. The normal pattern of movement of the anterior cusp is shown in Fig. I and consists of a rapid early diastolic opening followed immediately by closure to a semi-open position. At the onset of atrial systole the valve opens again, and this movement is followed by complete closure as the left ventricular pressure rises at the beginning of systole (Gustafson, 1967). The echogram was obtained by placing the transducer in the fourth left intercostal space $I$ to $5 \mathrm{~cm}$ from the sternal edge and adjusting the angulation until an optimal trace was obtained. All the recorded beats were subsequently analysed but only those in which the early diastolic opening movement occurred at a rate greater than $300 \mathrm{~mm}$ a second were accepted as technically satisfactory. Measurement of a valid diastolic closure rate at heart rates above 120 beats a minute was not possible as the atrial systolic opening movement merged with the early diastolic movement at these higher rates as a result of the short diastolic period (Fig. 2). Following the recording of the anterior cusp movement, the movement of the mitral valve ring was also measured in Cases 9 to 20 by slightly altering the angulation of the transducer superiorly and medially but without changing its position on the chest wall, until the characteristic pattern of movement of the valve ring was observed.

The 5 normal volunteers were studied not less than 6 hours after the last meal. The output of the ultrasound recorder was passed to a Cambridge multichannel photographic recorder using a matching amplifier. Simultaneous records were made of the electrocardiogram (lead II), phonocardiogram, and mitral echogram. The phonocardiogram was obtained using a piezoelectric crystal microphone placed in the second intercostal space at the left sternal edge. A small cannula was introduced into a vein on the dorsum of the hand and control recordings performed at a paper speed of $100 \mathrm{~mm}$ per second. An intravenous infusion of atropine sulphate was then started at a rate of $0.2 \mathrm{mg}$ every 2 minutes. Further recordings were made at 2-minute intervals until the heart rate reached 120 beats a minute or $\mathrm{I} .8 \mathrm{mg}$ atropine had been given.

In the second part of the study, 20 patients undergoing routine diagnostic cardiac catheterization were studied in the postabsorptive state. Recordings were made in the supine position before angiography and the patients were unsedated. Right and left heart catheterization was performed using conventional techniques. Pressures were recorded using either Sanborn type $267 \mathrm{Bc}$ or SE type 4-82 strain gauges and using the mid-thorax as the reference level. The left ventricular end-diastolic pressure was measured after the ' $a$ ' wave and the left ventricular end-systolic pressure at the lowest point in the ventricular pressure trace. The natural frequency of the catheter-transducer systems used varied from 25 to $35 \mathrm{~Hz}$ and additional mechanical damping was obtained using a modification of the method of Sutterer and Wood (1960).

In 17 patients the cardiac output was measured using the Fick direct oxygen method. Ventilation was measured either by a timed expired gas collection into a Douglas bag or by a pneumotachograph and computing spirometer (Mercury Electronics). Expired gas analysis was per-

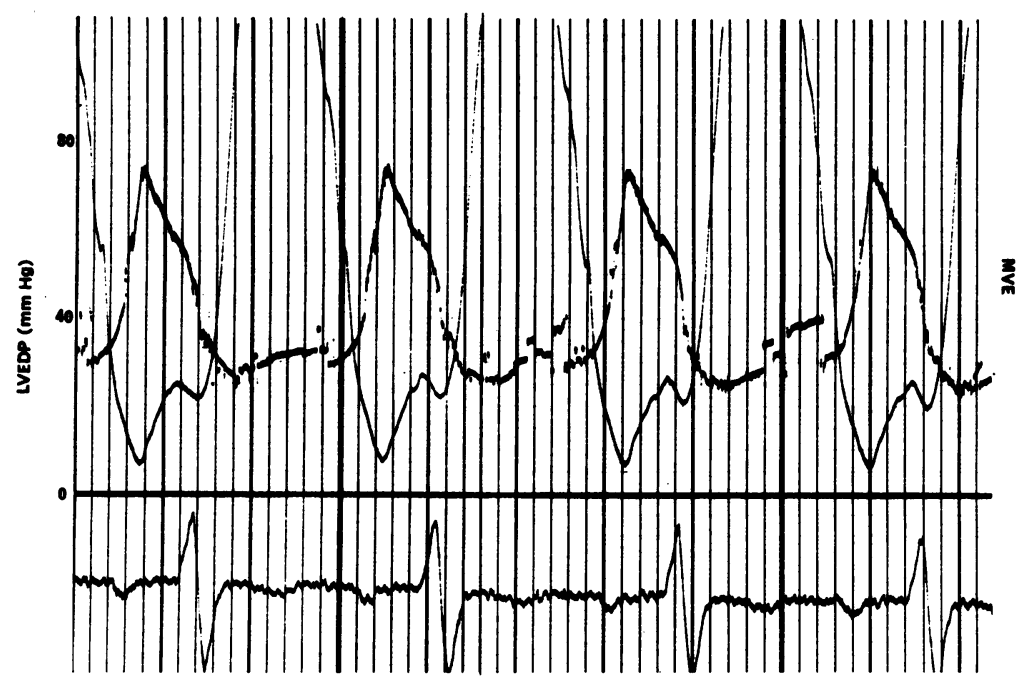

FIG. 2 The mitral echogram with simultaneous electrocardiogram and left ventricular diastolic pressure at higher heart rates. The atrial systolic opening movement is merging with the early diastolic movement. 
formed by physical techniques using a paramagnetic oxygen analyser (Servomex) and an infrared carbon dioxide analyser (Hartmann and Braun) calibrated with known gas concentrations. The haemoglobin and oxygen saturations of blood samples were measured on a COoximeter (IL Laboratories). The stroke volume was derived from the cardiac output and the heart rate, measured during the period of the collection of the expired air.

The electrocardiogram, intravascular pressures, and echograms were recorded using either a Hewlett-Packard multichannel photographic recorder or an SE Laboratories ultraviolet recorder at a paper speed of $100 \mathrm{~mm}$ a second.

In the first study the diastolic closure rate was compared with the heart rate derived from the preceding $R R$ interval on the electrocardiogram. In the second study the closure rate was related to the left ventricular filling pressure as measured by left ventricular end-diastolic pressure in 18 cases and pulmonary arterial diastolic pressure in 2 cases, and a regression equation was calculated. The slope of the regression lines for each subject was then plotted against the left ventricular diastolic $\Delta P / \Delta V$, which was derived from the difference between the end-diastolic and end-systolic pressures and the stroke volume. The constant of each regression equation was plotted against the total amplitude of movement of the mitral valve ring. The statistical significance of these relations was obtained by the calculation of correlation coefficients.

\section{Results}

In the first part of the study a total of $16 \mathrm{I}$ beats were technically acceptable for analysis. The ranges of the diastolic closure rate and the heart rates are shown in Table 2. The heart rates varied between 52 and II9 beats a minute and the diastolic closure rates from 58 to $139 \mathrm{~mm}$ a second. The mean diastolic closure rate for the group was $92 \mathrm{~mm}$ a second (SD $19 \mathrm{~mm}$ a second). The difference between highest and lowest diastolic closure rates varied from 21 to $44 \mathrm{~mm} / \mathrm{sec}$. No relation was found between the heart rate and the diastolic closure rate either for the group (Fig. 3) or for any individual subject.

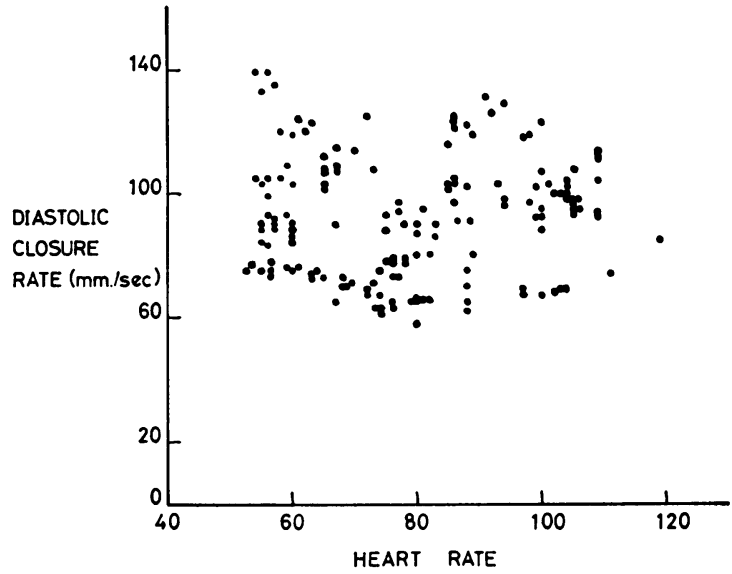

FIG. 3 The diastolic closure rate at different heart rates derived from the pooled observations in normal subjects.

In the second part of the study the haemodynamic data are shown in Table I. No attempt was made to alter the left ventricular filling pressure either by physical or pharmacological means, but the variation in pressure found in the subjects at rest ranged from 4.5 to $12.0 \mathrm{mmHg}$. This spontaneous variation in the pressure, largely related to the respiratory cycle, permitted the calculation of a regression equation for each subject relating the diastolic closure rate to the left ventricular filling pressure (Table 3, Fig. 4). In I7 of the 20 patients studied the linear relation between these two variables was highly significant $(P<0.001)$ (Fig. 5).

The three exceptions were Cases 7, 13, and 18, in whom changes in the left ventricular end-diastolic pressure produced only very small alteration in the diastolic closure rate resulting in a low coefficient of regression. In order to produce a relation with a high level of significance for these patients, a much larger range of pressures than were actually observed would have been required.

The mean left ventricular diastolic $\Delta \mathrm{P} / \Delta \mathrm{V}$ was

TABLE 2 Diastolic closure rate and heart rate during infusion of atropine

\begin{tabular}{lllllll}
\hline Case No. & $\begin{array}{l}\text { Heart rate } \\
\text { (beats/min) } \\
\text { Minimum }\end{array}$ & Maximum & $\begin{array}{l}\text { Diastolic closure-rate } \\
\text { (mm/sec) } \\
\text { Minimum }\end{array}$ & Mean & Maximum & $\begin{array}{l}\text { No. of beats } \\
\text { recorded }\end{array}$ \\
\hline 21 & 54 & 109 & 84 & 99 & 115 & 37 \\
22 & 52 & 89 & 75 & 84 & 97 & 23 \\
23 & 55 & 119 & 65 & 75 & 93 & 22 \\
24 & 54 & 106 & 95 & 112 & 139 & 48 \\
25 & 63 & 88 & 58 & 69 & 79 & 31 \\
\hline Total & 52 & 119 & 58 & 92 & 139 & I6I
\end{tabular}


TABLE 3 Relation between diastolic closure rate and left ventricular filling pressure in 20 subjects

\begin{tabular}{|c|c|c|c|}
\hline Case No. & $\begin{array}{c}\text { Regression equation } \\
\text { (diastolic closure rate }=\text { ) }\end{array}$ & $\begin{array}{l}\text { Correlation } \\
\text { coefficient }\end{array}$ & $P$ \\
\hline $\mathbf{I}$ & $6.0 \times \mathrm{LVFP}+37$ & 0.889 & $<0.001$ \\
\hline 2 & $3.4 \times L \mathrm{LFP}-\mathrm{I} 4$ & 0.834 & $<0.001$ \\
\hline 3 & $5.5 \times \mathrm{LVFP}+19$ & 0.863 & $<0.001$ \\
\hline 4 & $4.4 \times \mathrm{LVFP}+4$ & 0.804 & $<0.001$ \\
\hline 5 & $3.8 \times$ LVFP -4 & 0.812 & $<0.001$ \\
\hline 6 & $6.0 \times$ LVFP -27 & 0.925 & $<0.001$ \\
\hline 7 & $0.4 \times$ LVFP + I7 & 0.316 & $>0.1$ \\
\hline 8 & $4.0 \times L V F P+27$ & 0.854 & $<0.001$ \\
\hline 9 & $3 \cdot \mathrm{I} \times \mathrm{LVFP}+4$ & 0.848 & $<0.001$ \\
\hline IO & $6.9 \times$ LVFP +51 & 0.804 & $<0.001$ \\
\hline II & $7 \cdot 0 \times$ LVFP + 41 & 0.856 & $<0.001$ \\
\hline 12 & $3 \cdot 3 \times$ LVFP +22 & 0.875 & $<0.001$ \\
\hline 13 & $2 \cdot 1 \times L V F P+34$ & 0.613 & $<0.1$ \\
\hline 14 & $5.2 \times$ LVFP +43 & 0.781 & $<0.001$ \\
\hline 15 & $3.4 \times \mathrm{LVFP}+27$ & 0.762 & $<0.001$ \\
\hline 16 & $4.5 \times L V F P+26$ & 0.838 & $<0.001$ \\
\hline 17 & $5.0 \times$ LVFP -7 & 0.853 & $<0.001$ \\
\hline 18 & $\mathrm{I} \cdot 3 \times \mathrm{LVFP}+\mathrm{I} 8$ & 0.455 & $<0.1$ \\
\hline 19 & $4.0 \times$ LVFP - I2 & 0.886 & $<0.001$ \\
\hline 20 & $4.8 \times \mathrm{LVFP}+\mathrm{I7}$ & 0.878 & $<0.001$ \\
\hline
\end{tabular}

LVFP = left ventricular filling pressure.

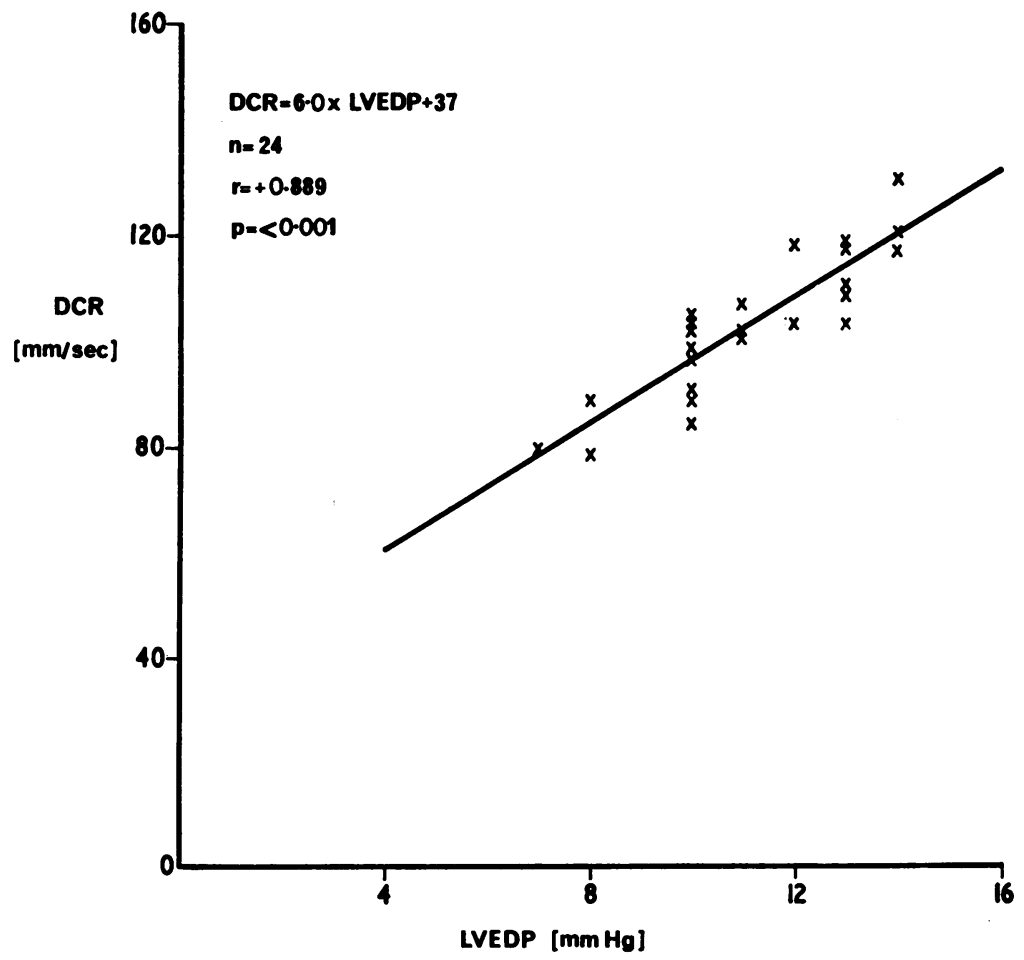

FIG. 4 The relation between the diastolic closure rate and the left ventricular end-diastolic pressure (Case I). 


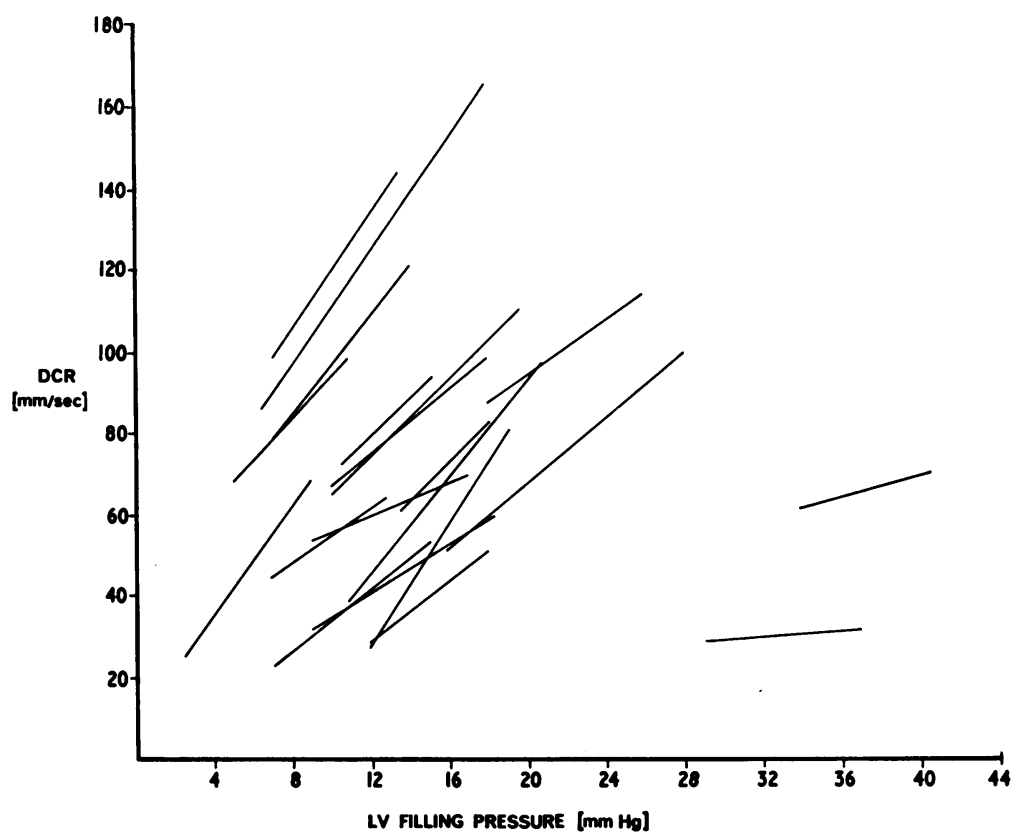

FIG. 5 The relation between the diastolic closure rate and the left ventricular filling pressure in 20 patients.

measured in 17 patients using 20 consecutive beats in the analysis. The slopes of the regression lines obtained from the relation between the diastolic closure rate and the left ventricular end-diastolic pressure were plotted against the left ventricular $\Delta \mathrm{P} / \Delta \mathrm{V}$ for the same subjects. Another highly significant linear relation $(P<0.001)$ was established between these variables (Fig. 6).

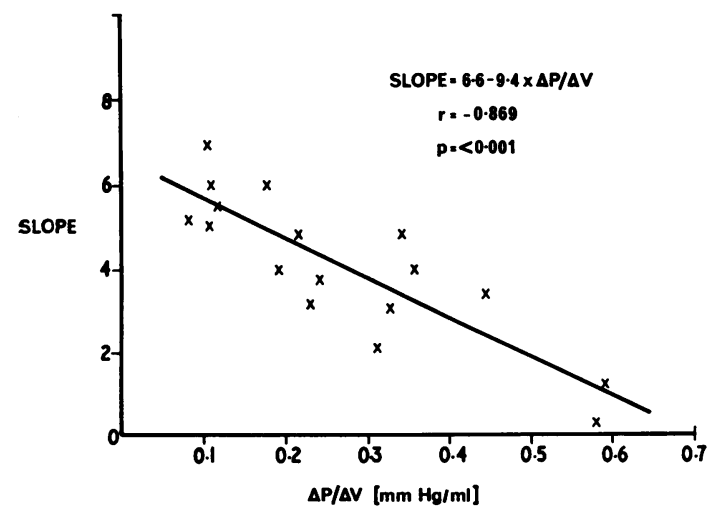

FIG. 6 The relation between the slopes of the regression lines and the left ventricular diastolic pressure/volume ratio.
The constants of the regression equations were plotted against the total amplitude of movement of the mitral valve ring in 12 of the subjects and a significant linear relation $(P<0.05)$ was found (Fig. 7). The range of amplitudes of movement of the mitral ring was 6.7 to $15.7 \mathrm{~mm}$.

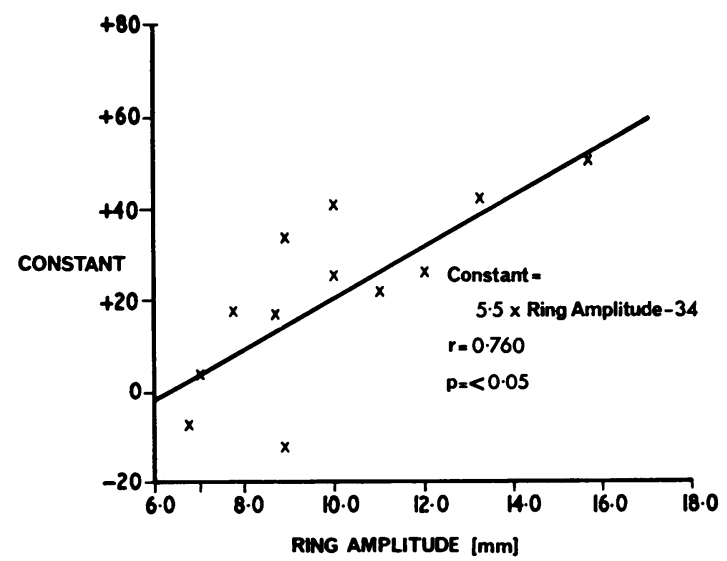

FIG. 7 The relation between the constants of the regression equations and amplitude of movement of the mitral valve ring. 


\section{Discussion}

The importance of measurement of the diastolic closure rate of the mitral valve has been recognized since the earliest reports on the use of ultrasound recordings of the movement of the anterior cusp. Ranges of normal values for the diastolic closure rate have been previously reported (Edler, 196I; Joyner, Reid, and Bond, 1963; Ziady et al., 1973). The values for the normal mean closure rate in this study are lower than expected from these earlier reports. However previous studies have used photographic recordings of slow-sweep oscilloscope traces for the analysis of the diastolic closure rate. Such measurements are of limited accuracy. This study has recognized the need for fast-sweep recordings in the measurement of time-based cardiovascular variables, and the differences observed in the mean values for the diastolic closure rate obtained for the normal subjects in this study as compared to previous reports are accounted for by this important difference in technique.

A reduction in the closure rate is a constant finding in mitral stenosis (Edler, 1967) but this has also been reported with hypertrophic cardiomyopathy (Popp and Harrison, 1969; Pridie and Oakley, 1970) and in the elderly without evidence of heart disease (Derman, 1972). In this study systemic hypertension, congestive cardiomyopathy, restrictive cardiomyopathy, and coronary artery disease have also been shown to be associated with an abnormally slow diastolic closure rate. This slow diastolic closure rate was found even in the presence of high left ventricular filling pressures and is in obvious contrast to the rapid diastolic closure rate seen in mitral and aortic regurgitation in which the filling pressure is also raised. This apparent paradox may be explained on the basis of the left ventricular filling rate as the major determinant of the diastolic closure rate, and, as has been previously suggested, with the left ventricular compliance as an important factor (Shabetai and Davidson, 1972).

In order to test the hypothesis of ventricular filling as the determinant of the diastolic closure rate this study has related the rate to the heart rate, ventricular filling pressure, and an index of ventricular diastolic compliance, the diastolic pressure/volume ratio. Only patients with normal valves were examined, in order to exclude the possibility of changes in the diastolic closure rate arising from an anatomical abnormality of the mitral valve interfering with its physical properties, and the presence of coincident disorders such as valvar regurgitation which would prevent the measurement of the left ventricular stroke volume.

Within the range of heart rates observed no change in the rate of left ventricular filling would be expected in the normal heart provided that the method used for the induction of the tachycardia had no other haemodynamic effects unrelated to the change in the heart rate (Weissler, Leonard, and Warren, 1957). The response of the cardiac output, stroke volume, and left ventricular filling pressure after infusion of atropine have been compared to those occurring during a similar tachycardia induced by atrial pacing, and no significant differences found (Kosowsky et al., 1966), suggesting that the use of atropine was valid. After large doses of atropine and at high heart rates there is a fall in the stroke volume and cardiac output accompanied by a fall in the ventricular filling pressure (Berry et al., 1959; McMichael and Sharpey-Schafer, 1944), but in this study these levels of tachycardia were not reached, thus validating the conclusion that the diastolic closure rate did not vary with changes in the heart rate and duration of diastole in normal subjects during a sinus tachycardia.

The relation between the diastolic closure rate and the left ventricular filling pressure can be expressed in the form of a linear regression equation (Table 3). The linearity of this relation is independent of the presence or absence of left ventricular pathology, and of the nature of that pathology, but there is considerable variation both with respect to the slope of the lines (representing the change in the diastolic closure rate for a $1 \mathrm{mmHg}$ change in the filling pressure) and the constant of the equation even within the group of patients with the same underlying disorder, namely coronary artery disease. The relation between the diastolic closure rate and the filling pressure seems, therefore, to be determined by a change in left ventricular diastolic properties rather than by the nature of the disease causing the change.

In a normal heart only small changes in the filling pressure are required to produce large variations in the stroke volume and ventricular filling. If the compliance of the left ventricle is impaired larger changes in the pressure will be required to maintain a similar change in the stroke volume and rate of filling. The relation between the filling pressure and the diastolic closure rate follows the same pattern, with a steep slope to the regression line in the normal heart and lower levels in the presence of disease causing impaired ventricular compliance.

Evidence to suggest that the diastolic closure rate and filling pressure relation is determined in part by the ventricular compliance is derived from the linear equation found to relate the slopes of the regression lines with the diastolic $\Delta \mathrm{P} / \Delta \mathrm{V}$. Measurements of the compliance of the left ventricle are difficult to evaluate because of the non-linearity of the pressure/ 
volume relation (Diamond et al., 197I). In an attempt to overcome this problem, measurements of diastolic $\Delta \mathrm{P} / \Delta \mathrm{V}$ have been used as an index of left ventricular wall stiffness (Adolph, 1965; Hood et al., 1970). However, it has been shown that $\Delta \mathrm{P} / \Delta \mathrm{V}$, which is an approximation for the instantaneous $\mathrm{dP} / \mathrm{dV}$, is affected by changes not only in the stiffness of the ventricular wall, but also, to a lesser extent, in its volume and contour (Diamond et al., I971; Diamond and Forrester, I972). Furthermore, there is some evidence to suggest that $\Delta \mathrm{P} / \Delta \mathrm{V}$ may also be dependent on the absolute level of the filling pressure (Diamond and Forrester, 1972). The $\Delta \mathrm{P} / \Delta \mathrm{V}$ is therefore not an acceptable measurement of left ventricular wall stiffness but remains a useful index of the mean pressure/volume relation and left ventricular diastolic properties. The linear relation between the $\Delta \mathrm{P} / \Delta \mathrm{V}$ and the slopes of the lines relating the diastolic closure rate to the filling pressure therefore strongly supports the hypothesis that the ventricular diastolic compliance is an important determinant of the diastolic closure rate as it is also the major factor in determining left ventricular $\Delta \mathrm{P} / \Delta \mathrm{V}$.

Since the anterior cusp of the mitral valve arises directly from the valve ring it has been assumed that the recorded movement of the cusp represents a composite of the movement of the two structures (Zaky, Nasser, and Feigenbaum, 1968). In systole the apparent movement of the cusp into the left ventricle can be entirely explained on the basis of ring movement. It is known that movement of the ring is in turn related to left ventricular function, and it has been used in the ultrasonic measurement of the stroke volume in conjunction with recordings of the motion of the interventricular septum and the left ventricular posterior wall (Feigenbaum, Zaky, and Nasser, 1967). Studies have also shown that the slow diastolic closure rate of the anterior cusp in mitral stenosis is related to the diminished amplitude of movement of the ring (Chakorn et al., 1972). The relation between the total amplitude of movement of the mitral valve ring and the constants of the regression equations relating the diastolic closure rate to the filling pressure allows for an assessment of the contribution of the ring movement to the closure rate.

The determinants of the diastolic closure rate of the mitral valve have been shown to include the left ventricular filling pressure and the diastolic pressure/ volume relation of the left ventricle and these findings strongly support the hypothesis that the diastolic closure rate is a reflection of the rate of left ventricular filling. However, in view of the importance of the movement of the mitral valve ring as a further determining factor, the interpretation of the diastolic closure rate as reflecting a particular filling rate must be made with caution. While, for example, the rapid diastolic closure rate associated with aortic regurgitation may be very largely related to the increased filling pressure and the absence of a significant reduction in the left ventricular compliance, the amplitude of the ring movement is also known to be increased (Chakorn et al., 1972; Zaky, Grabhorn, and Feigenbaum, 1967) (Table 4a). Before the change in the diastolic closure rate can be interpreted as reflecting a change in the ventricular filling rate, the component of the closure rate related to the ring movement must be excluded. Similar reservations in analysis apply with mitral regurgitation (Chakorn et al., 1972; Zaky et al., 1967) with the additional problem relating to a possible anatomical abnormality of the valve cusp. Conversely, low levels of the diastolic closure rate may reflect a slow rate of filling due to abnormal ventricular compliance, but impaired left ventricular systolic performance causing diminished amplitude of ring movement is also a factor (Table $4 \mathrm{~b}$ ). The absolute level of the diastolic closure rate is therefore not an indication of the state of the left ventricle. A normal diastolic closure rate may be found even in the presence of a reduction in compliance if the filling pressure is sufficiently high or the contribution of the ring movement increased (Table $4 \mathrm{c}$ ). If the

TABLE 4 Interrelation of left ventricular filling pressure, compliance, and amplitude of mitral ring movement in determining diastolic closure rate

\begin{tabular}{|c|c|c|c|}
\hline Filling pressure & Compliance & $\begin{array}{l}\text { Ring } \\
\text { amplitude }\end{array}$ & $\begin{array}{l}\text { Diastolic closure } \\
\text { rate }\end{array}$ \\
\hline a $\left\{\begin{array}{l}\text { High } \\
\text { Normal }\end{array}\right.$ & $\begin{array}{l}\text { Normal } \\
\text { Normal }\end{array}$ & $\begin{array}{l}\text { Normal } \\
\text { High }\end{array}$ & $\begin{array}{l}\text { Fast } \\
\text { Fast }\end{array}$ \\
\hline b $\left\{\begin{array}{l}\text { Normal } \\
\text { High } \\
\text { High }\end{array}\right.$ & $\begin{array}{l}\text { Low } \\
\text { Normal } \\
\text { Low }\end{array}$ & $\begin{array}{l}\text { Normal } \\
\text { Low } \\
\text { Low }\end{array}$ & $\begin{array}{l}\text { Slow } \\
\text { Slow } \\
\text { Slow }\end{array}$ \\
\hline c High & Low & Normal & Normal \\
\hline
\end{tabular}


diastolic closure rate is to be used as an index of ventricular filling it is important that the level of the filling pressure and amplitude of the ring movement be specified. Nevertheless, in many situations raised filling pressure may be anticipated from physical examination and the chest radiograph (Short, 1956). An inappropriately slow diastolic closure rate in the presence of such signs is evidence of abnormal ventricular compliance.

\section{References}

Adolph, R. J. (1965). Compliance of the apex of the left ventricle in unanesthetised dogs. Fournal of Applied Physiology, 20, 758.

Berry, J. N., Thompson, H. K., Miller, D. E., and McIntosh, H. D. (1959). Changes in cardiac output, stroke volume, and central venous pressure induced by atropine in man. American Heart fournal, 58, 204.

Chakorn, S. A., Siggers, D. C., Wharton, C. F. P., and Deuchar, D. C. (1972). Study of normal and abnormal movements of mitral valve ring using reflected ultrasound. British Heart fournal, 34, 480 .

Derman, U. (1972). Changes of the mitral echocardiogram with ageing and the influence of atherosclerotic risk factors. Atherosclerosis, 15, 349.

Diamond, G., and Forrester, J. S. (1972). Effect of coronary artery disease and acute myocardial infarction on left ventricular compliance in man. Circulation, 45, I I.

Diamond, G., Forrester, J. S., Hargis, J., Parmley, W. W., Danzig, R., and Swan, H. J. C. (I97I). Diastolic pressurevolume relationship in the canine left ventricle. Circulation Research, 29, 267.

Edler, I. (1956). Ultrasoundcardiogram in mitral valvular diseases. Acta Chirurgica Scandinavica, III, 230.

Edler, I. (196I). Atrioventricular valve motility in the living human heart recorded by ultrasound. Acta Medica Scandinavica, Suppl. 370, 83.

Edler, I. (1967). Ultrasoundcardiography in mitral valve stenosis. American fournal of Cardiology, 19, 18.

Feigenbaum, H., Zaky, A., and Nasser, W. K. (I967). Use of ultrasound to measure left ventricular stroke volume. Circulation, 35, 1092.

Gusatfson, A. (1967). Correlation between ultrasoundcardiography, hemodynamics and surgical findings in mitral stenosis. American fournal of Cardiology, 19, 32.

Hood, W. B., Bianco, J. A., Kumar, R., and Whiting, R. B. (1970). Experimental myocardial infarction: IV. Reduction of left ventricular compliance in the healing phase. fournal of Clinical Investigation, 49, 1316.

oyner, C. R., Reid, J. M., and Bond, J. P. (1963). Reflected ultrasound in the assessment of mitral valve disease. Circulation, 27, 503.

Kosowsky, B. D., Stein, E., Lau, S. H., Lister, J. W., Haft, J. I., and Damato, A. N. (I966). A comparison of the hemodynamic effects of tachycardia produced by atrial pacing and atropine. American Heart fournal, 72, 594.

McMichael, J., and Sharpey-Schafer, E. P. (1944). Cardiac output in man by a direct Fick method; effects of posture, venous pressure change, atropine and adrenaline. British Heart fournal, 6, 33.

Moreyra, E., Klein, J. J., Shimada, H., and Segal, B. L. (1969). Idiopathic hypertrophic subaortic stenosis diagnosed by reflected ultrasound. American fournal of Cardiology, 23, 32.

Popp, R. L., and Harrison, D. C. (1969). Ultrasound in the diagnosis and evaluation of therapy of idiopathic hypertrophic subaortic stenosis. Circulation, 40, 905.

Pridie, R. B. (1969). Mitral valve in aortic regurgitation (abstract). British Heart fournal, 3I, 797.

Pridie, R. B., and Oakley, C. M. (1970). Mechanism of mitral regurgitation in hypertrophic obstructive cardiomyopathy. British Heart fournal, 32, 203.

Segal, B. L., Likoff, W., and Kingsley, B. (1967). Echocardiography. Clinical application in mitral regurgitation. American fournal of Cardiology, 19, 50.

Shabetai, R., and Davidson, S. (1972). Asymmetrical hypertrophic cardiomyopathy simulating mitral stenosis. Circulation, 45, 37.

Shah, P. M., Gramiak, R., and Kramer, D. H. (r969). Ultrasound localization of left ventricular outflow obstruction in hypertrophic obstructive cardiomyopathy. Circulation, 40,3 .

Short, D. S. (1956). Radiology of the lung in left heart failure. British Heart fournal, 18, 233.

Sutterer, W. B., and Wood, E. H. (1960). Strain-gauge manometers: application to recording of intravascular and intracardiac pressures. In Medical Physics, Vol. 3, p. $64 \mathrm{I}$. Ed. by O. Glasser. Yearbook Publishers, Chicago.

Tallury, V. K., DePasquale, N. P., and Burch, G. E. (1972). The echocardiogram in papillary muscle dysfunction. American Heart fournal, 83, 12.

Weissler, A. M., Leonard, J. J., and Warren, J. V. (I957). Effects of posture and atropine on the cardiac output. fournal of Clinical Investigation, 36, 1656.

Zaky, A., Grabhorn, L., and Feigenbaum, H. (1967). Movement of the mitral ring: a study in ultrasoundcardiography. Cardiovascular Research, I, $12 \mathrm{I}$.

Zaky, A., Nasser, W. K., and Feigenbaum, H. (1968). A study of mitral valve action recorded by reflected ultrasound and its application in the diagnosis of mitral stenosis. Circulation, 37, 789.

Ziady, G., Madeira, H., Pridie, R., Callen, G., and Oakley, C. (1973). Diastolic closure rate of mitral valve as determined by ultrasound. In Proceedings of the British Cardiac Society. British Heart Fournal, 35, 560.

Requests for reprints to Dr. Clive Layton, Cardiac Department, The London Hospital, Whitechapel London EI IBB. 